\title{
The Secreted Protein Discovery Initiative (SPDI), a Large-Scale Effort to Identify Novel Human Secreted and Transmembrane Proteins: A Bioinformatics Assessment
}

\author{
Hilary F. Clark, ${ }^{1}$ Austin L. Gurney, Evangeline Abaya, Kevin Baker, Daryl Baldwin, \\ Jennifer Brush, Jian Chen, Bernard Chow, Clarissa Chui, Craig Crowley, \\ Bridget Currell, Bethanne Deuel, Patrick Dowd, Dan Eaton, Jessica Foster, \\ Christopher Grimaldi, Qimin Gu, Philip E. Hass, Sherry Heldens, Arthur Huang, \\ Hok Seon Kim, Laura Klimowski, Yisheng Jin, Stephanie Johnson, James Lee, \\ Lhney Lewis, Dongzhou Liao, Melanie Mark, Edward Robbie, Celina Sanchez, \\ jill Schoenfeld, Somasekar Seshagiri, Laura Simmons, Jennifer Singh, Victoria Smith, \\ Jeremy Stinson, Alicia Vagts, Richard Vandlen, Colin Watanabe, David Wieand, \\ Kathryn Woods, Ming-Hong Xie, Daniel Yansura, Sothy Yi, Guoying Yu, Jean Yuan, \\ Min Zhang, Zemin Zhang, Audrey Goddard, William I. Wood, and Paul Godowski \\ Departments of Bioinformatics, Molecular Biology and Protein Chemistry, Genentech, Inc., \\ South San Francisco, California 94080, USA
}

\begin{abstract}
A large-scale effort, termed the Secreted Protein Discovery Initiative (SPDI), was undertaken to identify novel secreted and transmembrane proteins. In the first of several approaches, a biological signal sequence trap in yeast cells was utilized to identify cDNA clones encoding putative secreted proteins. A second strategy utilized various algorithms that recognize features such as the hydrophobic properties of signal sequences to identify putative proteins encoded by expressed sequence tags (ESTs) from human cDNA libraries. A third approach surveyed ESTs for protein sequence similarity to a set of known receptors and their ligands with the BLAST algorithm. Finally, both signal-sequence prediction algorithms and BLAST were used to identify single exons of potential genes from within human genomic sequence. The isolation of full-length cDNA clones for each of these candidate genes resulted in the identification of $>1000$ novel proteins. A total of 256 of these cDNAs are still novel, including variants and novel genes, per the most recent GenBank release version. The success of this large-scale effort was assessed by a bioinformatics analysis of the proteins through predictions of protein domains, subcellular localizations, and possible functional roles. The SPDI collection should facilitate efforts to better understand intercellular communication, may lead to new understandings of human diseases, and provides potential opportunities for the development of therapeutics.
\end{abstract}

[Supplemental material is available online at www.genome.org and at http://share.gene.com. The cDNA clone sequences from this study have been submitted to GenBank under accession nos. AY358081-AY359127. The following individuals kindly provided reagents, samples, or unpublished information as indicated in the paper: $\mathrm{T}$. Wu.]

Discovery of novel human proteins provides new opportunities for development of drug therapies for treatment of the wide range of diseases for which there is still no cure. In other cases, these proteins play an integral role in a disease state or the biological pathway leading to disease, and their identification and characterization may lead to an understanding of disease paradigms. Secreted and transmembrane proteins, in particular, have properties that lend themselves to be utilized as therapeutic agents or targets. They are accessible to various drug delivery

\section{'Corresponding author.}

E-MAIL hclark@gene.com; FAX (650) 225-5389.

Article and publication are at http://www.genome.org/cgi/doi/10.1101/ gr.1293003. Article published online before print in September 2003. mechanisms, because they are presented on the cell surface or within the extracellular space. A purified secreted protein or a receptor extracellular domain can be utilized directly as a therapeutic (e.g., growth hormone), or may be targeted by specific antibodies or small molecules. Important therapeutics have been created that target proteins present on the cell surface in a specific cell type or disease state. Rituxan is an antibody therapeutic targeting the B lymphocyte-specific CD20 protein and is an effective therapeutic in the treatment of non-Hodgkin's lymphoma. Herceptin is an antibody therapeutic targeting the breast carcinoma-specific HER2 protein and is an effective therapeutic in the treatment of breast cancer.

A number of gene families of secreted and transmembrane 
proteins related by homology have emerged that include members known to have key roles in important biological processes such as morphogenesis, cellular differentiation, angiogenesis, apoptosis, and modulation of the immune response, as well as disease processes such as cancer progression. These gene families include tumor necrosis factors (Flavell 2002), growth factors (Hackel et al. 1999; Cross and Claesson-Welsh 2001; Ornitz and Itoh 2001; Danielsen and Maihle 2002), cytokines (Schooltink and Rose-John 2002), chemokines (Onuffer and Horuk 2002), interferons (Grandvaux et al. 2002), and angiopoietin-related (Yancopoulos et al. 1998) protein families, as well as the protein families of their receptors and other receptors such as the Tolllike receptors (Armant and Fenton 2002), integrins (Dedhar 1999), and disintegrins (Yamamoto et al. 1999; Tang 2001).

In some cases, a protein may have therapeutic potential if it is present in a disease state, even if it does not play a role in the progression or maintenance of the disease. However, there are many factors that influence a protein's potential as an effective and safe therapeutic or therapeutic target; the presence and abundance in normal and diseased tissues, the subcellular localization, the activity, and the biological role of the protein are just some of these factors. Therefore, it is imperative to screen a large number of proteins for a wide variety of such characteristics in order to identify the most promising potential candidates for drug development. Computational methods can be useful in predicting the likelihood of some of a protein's characteristics in order to focus further laboratory investigation on the proteins with the most potential for playing a role in a disease state and leading to a therapeutic. To facilitate the discovery of new therapeutic opportunities, we undertook a large-scale program of biological and computational strategies to identify and classify new secreted and transmembrane proteins.

\section{RESULTS}

This effort to identify novel secreted and transmembrane human proteins resulted in 1047 transcripts successfully cloned, representing 1021 genes (Table 1). A complete list of the GenBank accession numbers of the cDNA clone sequences with details of the analysis summarized in this publication is available as a Supplementary Table. The success rate of the SPDI project can be measured by the proportion of these genes that appear to encode secreted or transmembrane proteins, which is $86 \%$ ( 879 genes). A total of $13 \%$ (136 genes) appear to encode cytoplasmic and nuclear proteins, and the subcellular localization could not be predicted for $1 \%$ (6 genes). Because our identification of these transcripts as representing novel genes, $77 \%$ (791) of them have been submitted to GenBank from sources other than this SPDI effort (Table 2). However, 25\% of these cDNAs are still unique transcripts. This includes $20 \%$ (209) that are variants of genes currently represented in GenBank and 5\% (47) that may represent completely novel genes.

A number of SPDI transcripts still represent novel genes at the time of the submission of this work. Evidence of these being bonafide genes includes ESTs, homology with known protein domains, and orthology with a mouse gene. Such evidence is present for most of the novel SPDI transcripts (Table 3). Transcripts with none of this evidence may also represent bonafide genes, but those with small predicted proteins may be more likely to be partial transcripts or other artifacts. Nonetheless, almost all of the SPDI transcripts that initially lacked supporting evidence have been confirmed by cDNAs identified by others over the years.

The first approach to the identification of novel secreted proteins was to exploit biological screens for the ability of cDNA
Table 1. Gene Categorization

Gene/domain category

No. of genes

7 Transmembrane domain receptors 9

Acyltransferases

Alcohol dehydrogenases

Amino oxidases

AMP binding proteins

C1q domain receptors

Cadherins

Carbonic anhydrases

Carboxylesterases

Carboxypeptidases

Claudins

Collagens

CUB/Sushi domain receptors

Cystatins

Cytochromes

Cytokines and chemokines

Epidermal growth factor receptors

Epidermal growth factors

Fibrinogens

Fibroblast growth factors

Fibronectins

Glypicans

Hormones

Integrins

Interferons

Laminins

Lectins

Leucine-rich repeat receptors

Lipocalins

Low-density lipoprotein receptors

Membrane channels

Olfactomedins

Peptidases

Phosphodiesterases

Proteases and protease inhibitors

Scavenger receptor domain proteins

Semaphorins and plexin repeat receptors

Thrombospondins and ADAMs

Transforming growth factors

Trypsins and trypsin inhibitors

Tumor necrosis factor receptors

Tumor necrosis factors

Tyrosine kinase receptors

Uteroglobins

WNT and WNT induced signaling proteins

Other immunoglobulin superfamily

Other secreted proteins

Other transmembrane proteins

Total number of secreted and transmembrane proteins

Galactosyltransferases

Glycosyltransferases

Kinases

Mitochondrial carrier proteins

Sulfatases

Sulfotransferases

Thioredoxins

Transcription factors

Other cytoplasmic and nuclear

Total number of cytoplasmic and nuclear proteins

Total number of proteins with unpredicted localization

Total number of SPDI genes

Gene families and categories as determined by computational assessment of protein domains and sub-cellular localization, as well as curation.

library-encoded fusion proteins to direct the secretion of a reporter protein. Yeast cells provide an easily manipulated system for such screens for secreted proteins (Klein et al. 1996; Baker and

\section{Genome Research}


Table 2. Novelty Assessment of Transcripts Identified

\begin{aligned} $\begin{array}{r}\text { No. of } \\ \text { cDNAs }\end{array} & \multicolumn{1}{c}{$ Comparison to other GenBank cDNAs } \\ \hline 791 & $\begin{array}{l}\text { Identity with GenBank CDNA currently in GenBank from } \\ \text { source other than this SPDI effort } \\ \text { Variant of gene with CDNAs in GenBank }\end{array} \\ 209 & \begin{array}{l}\text { No other GenBank CDNAs for this gene } \\ 47\end{array} \\ 1047 &$ Total number of cDNAs included in the SPDI collection \end{aligned}

Determined just prior to this publication by BLAST algorithm against GenBank using the ORF sequence (all sequences were absent from GenBank when identified).

Gurney 2000). Large libraries of cDNA fragments inserted before the reporter gene can be screened, and positive yeast colonies secreting the fusion reporter protein can then be identified. PCR amplification of the cDNA insert from the yeast colony allows sequence identification of cDNA clones encoding functional secretion sequences.

One difficulty inherent in biological screens for secreted proteins is that they encounter diminishing yields as the more abundant novel proteins are discovered and the remaining novel proteins become more rare. Computational methods, by comparison, are in principle, well suited to the identification of rare genes, provided there is sequence information to analyze. The overall SPDI strategy was to use both biological and computational methods to identify novel secreted and transmembrane proteins from multiple sources of DNA sequence (Fig. 1). The availability of very large collections of ESTs has greatly facilitated the use of such computational strategies. Two algorithms that detect the properties of signal peptides were developed and utilized, Signal Sensor (C. Watanabe, unpubl.) and Sighmm (Zhang and Wood 2003); both measure the hydropathy of the amino terminus of DNA translations that may encode proteins. Both are effective at identifying signal peptides with robust sensitivities and specificities.

Some proteins known to be secreted or membrane bound cannot currently be identified as such computationally and/or do not possess a signal peptide. Additionally, limitations to the EST collections result in some genes not being represented with EST coverage containing amino-terminal sequence information. However, these proteins may have amino acid sequence homology to known secreted and transmembrane proteins. This homology may suggest a similar role and subcellular localization. Thus, homology-based screening strategies can be a powerful tool to identify putative secreted and transmembrane proteins. We utilized a collection of known ligands and receptors of interest as a homology-based method of identifying new members of these protein families. The protein families used in this search represent key players in cell-cell signaling, such as growth factors, cytokines, chemokines, and their receptors.

The recent availability of large-scale genomic sequence has provided new opportunities to identify rare genes not abundantly present within cDNA libraries and EST collections. The presence of introns in genomic sequence requires that a geneprediction algorithm such as Genscan be used for gene identification. We have utilized both signal-sequence detection strategies and homology-based approaches to mine both predicted genes and genomic sequence directly for the identification of additional genes.

The SPDI effort utilized multiple gene-identification strategies that were used at different times during the course of the project, and genes already identified by one strategy were bypassed with later strategies. For this reason, it is not possible to evaluate which strategy was most effective at identifying secreted and transmembrane proteins. However, the largest number of genes were identified in this effort by computational signal sequence or homology detection from ESTs (Table 4). The smallest number of genes were detected only from genomic sequence. EST evidence was not sufficient for identification of these genes because of their rarity of expression, as EST coverage did not include a signal sequence, or because they are not highly homologous to the known ligands and receptors used to identify family members. For some genes, multiple methods were required in an iterative strategy in order to attain a full-length cDNA clone. Often, this occurred for particularly long transcripts when a $5^{\prime}$ truncated transcript was identified by EST mining, and then genomic sequence mining revealed the first exon of the gene. The SPDI effort exemplifies the value of utilizing various complementary approaches of gene identification.

Many of the genes identified belong to gene families related by homology, which are known to include important regulators of key physiological processes. These include secreted proteins such as cytokines, chemokines, and growth factors and their receptors. Other genes, such as those that apparently encode cytoplasmic or nuclear proteins, were also identified. In some cases, this was due to the presence of domains such as protease domains that can occur in proteins localized to either intracellular or extracellular spaces. The families of proteins that were found to have the greatest number of new members through this effort were the immunoglobulin (Ig) domain and leucine-rich repeat proteins. Combined, these two structural domains were present in $>10 \%$ of the proteins identified. Another $10 \%$ of the proteins are clearly related to known classes of enzymes. A number of these proteins appear to be localized within subcompartments of secretory pathways and may have roles in regulating protein post-translational modification (e.g., glycoslation). Perhaps surprisingly, new members were identified for most of the major known families of secreted proteins. In some cases, such as in the interferon family, new members were identified despite the considerable previous efforts to identify members of the family.

\section{DISCUSSION}

The success of this effort was due to the combined use of multiple strategies for the identification of genes that encode secreted and transmembrane molecules. Each strategy has different strengths and limitations. The strategies were directed at both the source of gene evidence, such as ESTs, and both predicted gene and exon homology from genomic sequence, and at the method of detecting putative proteins with the properties of secreted and transmembrane proteins including biological screens for secretion, algorithms for detecting signal sequences, and homology searches based on a collection of known secreted and transmembrane proteins of interest.

The various methods described have differed in their success at identifying particular types of genes. For instance, novel secreted genes without a recognizable relationship to other known genes can perhaps only be identified with the biological or computational signal-sequence detection methods. Conversely, many secreted and transmembrane proteins of known gene families do not have a detectable signal sequence (e.g., basic FGF), but could be recognized by homology. The success rate of these methods was also influenced by the timing of their introduction. For example, the yeast signal trap screening was gradually discontinued as EST collections became larger and proved to be a more efficient means of gene identification. Similarly, genomic sequence mining was introduced only after EST mining had been fairly exhaustive. 
Table 3. Novel Genes

\begin{tabular}{|c|c|c|c|c|c|}
\hline $\begin{array}{l}\text { Genentech } \\
\text { UNQ ID }\end{array}$ & Name & $\begin{array}{l}\text { Predicted } \\
\text { protein (aa) }\end{array}$ & $\begin{array}{l}\text { Predicted } \\
\text { domains }\end{array}$ & $\begin{array}{l}\text { Mouse ortholog } \\
\text { LocusLink }\end{array}$ & $\begin{array}{c}\text { EST } \\
\text { evidence }\end{array}$ \\
\hline 9220 & RRLF9220 & 250 & & & \\
\hline 9392 & VLLR9392 & 199 & & & \\
\hline 9218 & CMRF35A4 & 194 & ig & 140497 & \\
\hline 6494 & QCWQ6494 & 183 & & & Yes \\
\hline 6490 & YPLR6490 & 168 & & & Yes \\
\hline 5809 & AVLL5809 & 159 & & 66925 & Yes \\
\hline 6126 & LPEQ6126 & 157 & & & \\
\hline 9438 & TIMM9 & 152 & & & \\
\hline 6487 & LMNE6487 & 150 & & & Yes \\
\hline 751 & HHSL751 & 143 & & & \\
\hline 6167 & NINP6167 & 142 & & & Yes \\
\hline 3061 & GLLV3061 & 139 & & & Yes \\
\hline 9165 & AALS9165 & 137 & & & Yes \\
\hline 6190 & AGVR6190 & 127 & & & \\
\hline 9374 & VCEW9374 & 127 & & & \\
\hline 3057 & VFLL3057 & 126 & & & \\
\hline 430 & RGTR430 & 125 & UPAR_LY6 & 68311 & Yes \\
\hline 1945 & VLGN1945 & 125 & & & \\
\hline 6493 & EPWW6493 & 122 & & & \\
\hline 9368 & RTFV9368 & 120 & & & \\
\hline 3118 & GRTR3118 & 119 & & & Yes \\
\hline 9364 & FLFF9364 & 118 & & & \\
\hline 3104 & АCAH3104 & 115 & & & \\
\hline 9353 & micronovel & 115 & & & \\
\hline 5815 & QIQN5815 & 114 & & & \\
\hline 6228 & MRSS6228 & 114 & & & Yes \\
\hline 3029 & VLCS3029 & 113 & & & \\
\hline 3112 & LVLF3112 & 113 & & & Yes \\
\hline 6125 & ARVP6125 & 108 & & & \\
\hline 2550 & SFVP2550 & 103 & & & \\
\hline 3028 & TSSP3028 & 102 & & & Yes \\
\hline 6249 & KLIA6249 & 102 & & & Yes \\
\hline 2999 & GNNC2999 & 100 & & & \\
\hline 9419 & AHPA9419 & 99 & & & \\
\hline 5830 & AILT5830 & 95 & & & \\
\hline 2786 & PIKR2786 & 93 & & & Yes \\
\hline 3106 & KVVM3106 & 93 & Uteroglobin & & Yes \\
\hline 6489 & GWSI6489 & 91 & & & Yes \\
\hline 5840 & VGSA5840 & 90 & & & Yes \\
\hline 5836 & HSAL5836 & 89 & & & Yes \\
\hline 1944 & RVLA1944 & 88 & & & Yes \\
\hline 6484 & ISPF6484 & 88 & & & \\
\hline 6488 & AAGG6488 & 85 & & & Yes \\
\hline 1948 & AVPC1948 & 83 & & & \\
\hline 3035 & LCII3035 & 78 & & & \\
\hline 1829 & FRSS1829 & 73 & & & \\
\hline 466 & GVEI466 & 52 & & & Yes \\
\hline
\end{tabular}

Characteristics of genes represented in GenBank solely by CDNAs from this SPDI program as of July 16, 2003. EST evidence and domain prediction are described in Materials and Methods, but only PFAM domains are noted here. Mouse orthologs have been identified for some of these genes, but that assessment is not comprehensive.

induces proliferation, migration, and fenestration in capillary endothelial cells derived from endocrine glands (LeCouter et al. 2001).

Cytokines and their receptors transmit signals that modulate the immune response. The IL$17 \mathrm{~B}$ and IL-17C cytokines induce the release of the TNF- $\alpha$ and IL-1 $\beta$ cytokines from monocytic immune cells (Li et al. 2000). The IL17E cytokine binds the cytokine receptor IL17Rh1 and induces activation of the NF-kB-signaling pathway and release of the proinflammatory cytokine IL-8 (Lee et al. 2001). The IL-22 cytokine mediates the JAKSTAT signaling pathway on binding its receptors CRF2-4 and IL-22R (Xie et al. 2000). GLM-R is a type-1 cytokine receptor that signals cellular proliferation in the immune system (Ghilardi et al. 2002). The cytokine receptor TCCR is critical for the generation of the adaptive immune response mediated by T-helper cells of the Th1 subset (Chen et al. 2000).

Tumor necrosis factors and their receptors are involved in a number of physiological and pathological responses. DR5 induces apoptosis in tumor cells after binding Apo2L/TRAIL, and DcR1 and DcR2 act as decoy receptors that inhibit this signaling (Marsters et al. 1997; Sheridan et al. 1997). Apo3L induces apoptosis and activatation of the NF$\mathrm{kB}$ signaling pathway after binding Apo3/DR3 (Marsters et al. 1998). DcR3 is a soluble decoy receptor that inhibits apoptosis on binding Fas ligand (Pitti et al. 1998). GITRL activates the NF-kB signaling pathway on binding to its receptor GITR and protects T-lymphocytes against apoptosis-induced cell death (Gurney et al. 1999). XEDAR induces the NF-kB signaling pathway on binding its ligand, an isoform of ectodysplasin (Yan et al. 2000).

The innate immune system uses Toll family receptors to signal for the presence of microbes and initiate host defense. Bacterial lipoproteins are potent activators of Toll-like receptor-2, mediating both apoptosis and NF-kB signaling through myeloid differentation factor 88 (Yang et al. 1998; Aliprantis et al. 2000). Flagellin, the structural component of bacterial flagella, is detected by Toll-like receptor-5, which mediates inflammatory responses to Salmonella (Gewirtz et al. 2001).

A number of the SPDI proteins have been implicated in a wide range of other biological processes, and further investigation of others is underway (Pennica et al. 1998; Xie et al. 1999; Holcomb et al. 2000). Currently, microarray expression data from a wide array of normal and

The novelty of these proteins was a key factor in the criteria for cloning them. Candidates that had identity to cDNA clone sequences in GenBank were not pursued. Therefore, the genes identified do not represent a complete collection of secreted and transmembrane proteins. Large-scale efforts by others have also identified comprehensive collections of cDNA clones for human (Strausberg et al. 1999) and mouse (Kawai et al. 2001) genes.

Many proteins in the SPDI collection have already been shown to have functions in important biological processes through investigations with the cDNA clones identified here. Of particular interest have been newly identified growth factors, cytokines, tumor necrosis factors, and Toll family receptors. Angiogenic mitogens stimulate growth of vascular endothelial cells, which is critical to the development of vascular supply. EG-VEGF diseased cells and tissues is providing valuable information about possible utility for many of these genes in the treatment of cancer and immune diseases. The ongoing challenge for researchers is to continue to develop and explore new genomic scale approaches to best utilize the rich trove of sequence information that has been made possible by this and other efforts to discover and define the genes encoded within the human genome.

\section{METHODS}

\section{Biological Screens in Yeast Cells for Detection of Secretion Sequences}

Recombinant gene libraries were constructed by replacing the signal peptide encoded by the reporter gene with a library of

\section{Genome Research}




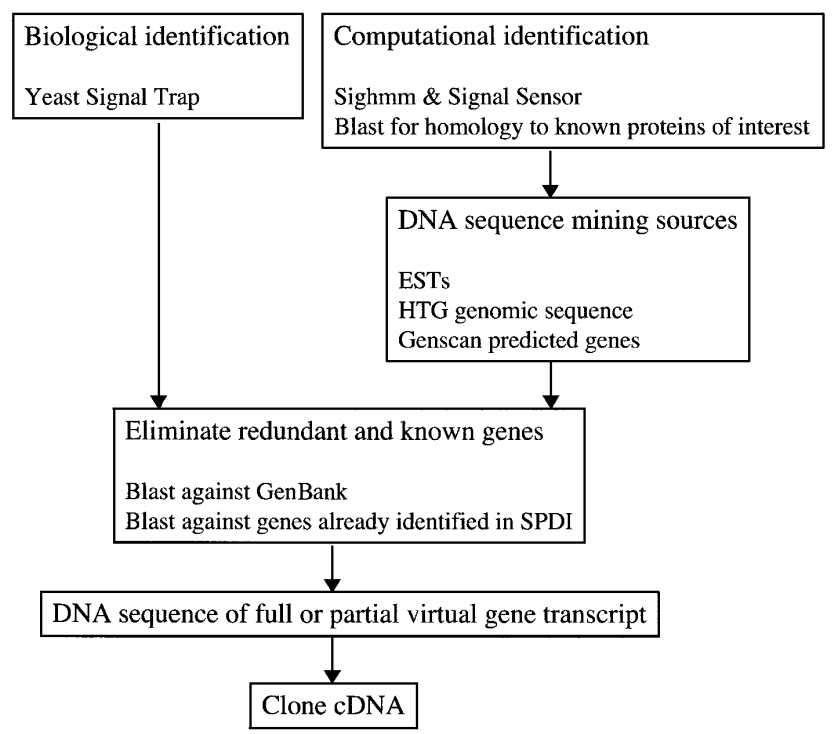

Figure 1 SPDI flow diagram.

cDNA fragments. If a given cDNA fragment encodes a signal peptide, the fusion protein may be secreted by a clonal colony of yeast cells, enabling identification of functional signal sequences. Several reporter genes were utilized in these studies, including invertase, amylase (Klein et al. 1996; Baker and Gurney 2000), and the yeast enzyme BAR1 (V. Smith, unpubl.). In brief, yeast colonies were identified that were positive for secretion of the reporter protein. The cDNA fragment contained within the fusion gene was then isolated by PCR and sequenced. Those cDNA fragments that appeared to encode ORFs containing signal sequence motifs were then further characterized by isolation of corresponding full-length cDNA clones.

\section{Sequence Data Sources for Computational Screens}

ESTs from both public (Lennon et al. 1996) and private (Incyte Pharmaceuticals) collections were utilized. ESTs were mined from consensus sequences of EST clusters, as well as individually. Genomic sequence was also mined, both directly from the human high-throughput sequence (HTG) available in the GenBank database, and through an internally compiled database of proteins predicted by the Genscan algorithm (Burge and Karlin 1997) from the HTG sequence. cDNA libraries were screened to isolate corresponding full-length cDNA clones. In some cases, the cDNA clones represented by an EST identified in these screens were purchased from private (Incyte Pharmaceutical) and public (Williamson 1999) sources.

\section{Computational Screen for Signal Peptides}

The Signal Sensor (C. Watanabe, unpubl.) and Sighmm (Zhang and Wood 2003) algorithms were used to detect signal peptides at the amino terminus of a putative protein sequence in an EST or Genscan-predicted protein.

\section{Computational Screen for Homology to Proteins of Interest}

A collection of known secreted and transmembrane proteins from gene families that include members with demonstrated biological function of particular interest (see Introduction) was used as query sequences with the BLAST algorithm against EST, genomic, and predicted protein databases. The Pfam database was queried using hmmpfam (Eddy 1998; Sonnhammer et al. 1998; Bateman et al. 2002) with each of these known proteins to determine protein domains that are represented in these protein families.

\section{Novelty Assessment of Identified Transcripts}

An automated computer algorithm was written to assess the novelty of each sequence, using only the ORF queried by the BLAST algorithm against GenBank. Identity was defined as at least $96 \%$ identity over the length of the ORF minus no greater than $36 \mathrm{bp}$ ( 6 amino acids). A variant is defined as the top BLAST hit to a GenBank entry without identity, but a match of at least $100 \mathrm{bp}$ with at least $96 \%$ identity. This identifies both splice variants and truncated versions of the same protein. Sequences that had no identity or variant in GenBank were further queried against GenBank ESTs by BLAST. EST evidence was determined by a match of at least $80 \mathrm{bp}$ with at least $96 \%$ identity.

\section{Prediction of Protein Domains and Subcellular Localization}

An automated computational strategy was utilized to query each protein translation with the Signal Sensor, Sighmm, Tmdetect (T. Wu, unpubl.), hmmpfam (Eddy 1998), and Protcomp (Softberry, Inc.) algorithms. As described earlier, the Signal Sensor and Sighmm algorithms predict a secretion signal sequence. The Tmdetect algorithm predicts a transmembrane domain. The hmmpfam algorithm queries the Pfam database of protein domains to predict function domains of proteins that are related by sequence homology. The Protcomp algorithm predicts the subcellular localization of a protein, on the basis of homology to wellannotated proteins, a neural net, and various protein motifs.

\section{Assignment of Transcipts to Gene Categories}

The Gene Categories in Table 1 were determined by an iterative analysis of protein domain and protein localization predictions from various algorithms to assess the likely subcellular localization and putative functional role of each protein. In general, the genes have been divided into "Secreted and Transmembrane Proteins" and "Cytoplasmic and Nuclear Proteins", for the purpose of evaluating the success of this effort to identify secreted and transmembrane proteins. Further subcategories are delineated, in which categories of particular interest or preponderance became apparent. The categorization of proteins was determined first by domains. Some curation was done to evaluate the hmmpfam scores and determine whether the Pfam domain seemed valid, as well as consideration of the signal sequence and transmembrane domain predictions in that context. A number of genes had no signal sequence, transmembrane, or Pfam domains predicted. In this case, the Protcomp subcellular localization prediction was used to categorize these genes as "Other Secreted", "Other Transmembrane", or "Other Cytoplasmic or Nuclear".

\section{ACKNOWLEDGMENTS}

We thank Thomas $\mathrm{Wu}$ for the Tmdetect algorithm and David Carpenter for fruitful analysis and discussions.

The publication costs of this article were defrayed in part by payment of page charges. This article must therefore be hereby

Table 4. Assessment of the Contribution by Multiple Identification Methods

\begin{tabular}{lc}
\hline Primary identification method & $\begin{array}{c}\text { Genes } \\
\text { identified }\end{array}$ \\
\hline Yeast signal sequence trap & 117 \\
Computational signal sequence detection from ESTs & 335 \\
Computational signal sequence detection from & 27 \\
genomic sequence & 521 \\
Computational homology detection from ESTs & 25 \\
Computational homology detection from genomic & \\
sequence & 21 \\
\hline
\end{tabular}

Determined by primary identification method. 
marked "advertisement" in accordance with 18 USC section 1734 solely to indicate this fact.

\section{REFERENCES}

Aliprantis, A.O., Yang, R.B., Weiss, D.S., Godowski, P., and Zychlinsky, A. 2000. The apoptotic signaling pathway activated by Toll-like receptor-2. EMBO J. 19: 3325-3336.

Armant, M.A. and Fenton, M.J. 2002. Toll-like receptors: A family of pattern-recognition receptors in mammals. Genome Biol. 3: 3011-3016.

Baker, K. and Gurney, A.L. 2000. Method of selection for genes encoding secreted and transmembrane proteins. In US Patent $6,060,249$

Bateman, A., Birney, E., Cerruti, L., Durbin, R., Etwiller, L., Eddy, S.R., Griffiths-Jones, S., Howe, K.L., Marshall, M., and Sonnhammer, E.L. 2002. The Pfam protein families database. Nucleic Acids Res. 30: $276-280$.

Burge, C. and Karlin, S. 1997. Prediction of complete gene structures in human genomic DNA. J. Mol. Biol. 268: 78-94.

Chen, Q., Ghilardi, N., Wang, H., Baker, T., Xie, M.H., Gurney, A., Grewal, I.S., and de Sauvage, F.J. 2000. Development of Th1-type immune responses requires the type I cytokine receptor TCCR. Nature 407: 916-920.

Cross, M.J. and Claesson-Welsh, L. 2001. FGF and VEGF function in angiogenesis: Signalling pathways, biological responses and therapeutic inhibition. Trends Pharmacol. Sci. 22: 201-207.

Danielsen, A.J. and Maihle, N.J. 2002. The EGF/ErbB receptor family and apoptosis. Growth Fact. 20: $1-15$.

Dedhar, S. 1999. Integrins and signal transduction. Curr. Opin. Hematol. 6: $37-43$.

Eddy, S.R. 1998. Profile hidden Markov models. Bioinformatics 14: $755-763$.

Flavell, R.A. 2002. The relationship of inflammation and initiation of autoimmune disease: Role of TNF super family members. Curr. Top. Microbiol. Immunol. 266: 1-10.

Gewirtz, A.T., Navas, T.A., Lyons, S., Godowski, P.J., and Madara, J.L. 2001. Cutting edge: Bacterial flagellin activates basolaterally expressed TLR5 to induce epithelial proinflammatory gene expression. J. Immunol. 167: 1882-1885.

Ghilardi, N., Li, J., Hongo, J.A., Yi, S., Gurney, A., and de Sauvage, F.J. 2002. A novel type I cytokine receptor is expressed on monocytes, signals proliferation, and activates STAT-3 and STAT-5. J. Biol. Chem. 277: 16831-16836.

Grandvaux, N., tenOever, B.R., Servant, M.J., and Hiscott, J. 2002. The interferon antiviral response: From viral invasion to evasion. Curr. Opin. Infect. Diseases 15: 259-267.

Gurney, A.L., Marsters, S.A., Huang, A., Pitti, R.M., Mark, M., Baldwin, D.T., Gray, A.M., Dowd, P., Brush, J., Heldens, S., et al. 1999. Identification of a new member of the tumor necrosis factor family and its receptor, a human ortholog of mouse GITR. Curr. Biol. 9: $215-218$.

Hackel, P.O., Zwick, E., Prenzel, N., and Ullrich, A. 1999. Epidermal growth factor receptors: Critical mediators of multiple receptor pathways. Curr. Opin. Cell Biol. 11: 184-189.

Holcomb, I.N., Kabakoff, R.C., Chan, B., Baker, T.W., Gurney, A., Henzel, W., Nelson, C., Lowman, H.B., Wright, B.D., Skelton, N.J., et al. 2000. FIZZ1, a novel cysteine-rich secreted protein associated with pulmonary inflammation, defines a new gene family. EMBO J. 19: 4046-4055.

Kawai, J., Shinagawa, A., Shibata, K., Yoshino, M., Itoh, M., Ishii, Y., Arakawa, T., Hara, A., Fukunishi, Y., Konno, H., et al. 2001. Functional annotation of a full-length mouse cDNA collection. Nature 409: 685-690.

Klein, R.D., Gu, Q., Goddard, A., and Rosenthal, A. 1996. Selection for genes encoding secreted proteins and receptors. Proc. Natl. Acad. Sci. 93: $7108-7113$.

LeCouter, J., Kowalski, J., Foster, J., Hass, P., Zhang, Z., Dillard-Telm, L., Frantz, G., Rangell, L., DeGuzman, L., Keller, G.A., et al. 2001. Identification of an angiogenic mitogen selective for endocrine gland endothelium. Nature 412: 877-884.

Lee, J., Ho, W.-H., Maruoka, M., Corpuz, R.T., Baldwin, D.T., Foster, J.S., Goddard, A.D., Yansura, D.G., Vandlen, R.L., Wood, W.I., et al. 2001. IL-17E, a novel proinflammatory ligand for the IL-17 receptor homolog IL-17Rh1. J. Biol. Chem. 276: 1660-1664.

Lennon, G., Auffray, C., Polymeropoulos, M., and Bento Soares, M. 1996. The I.M.A.G.E. consortium: An integrated molecular analysis of genomes and their expression. Genomics 33: 151-152.

Li, H., Chen, J., Huang, A., Stinson, J., Heldens, S., Foster, J., Dowd, P., Gurney, A.L., and Wood,W.I. 2000. Cloning and characterization of IL-17B and IL-17C, two new members of the IL-17 cytokine family. Proc. Natl. Acad. Sci. 97: 773-778.

Marsters, S.A., Sheridan, J.P., Pitti, R.M., Huang, A., Skubatch, M., Baldwin, D., Yuan, J., Gurney, A., Goddard, A.D., Godowski, P., et al. 1997. A novel receptor for Apo2L/TRAIL contains a truncated death domain. Curr. Biol. 7: 1003-1006.

Marsters, S.A., Sheridan, J.P., Pitti, R.M., Brush, J., Goddard, A., and Ashkenazi, A. 1998. Identification of a ligand for the death-domain-containing receptor apo3. Curr. Biol. 8: 525-528.

Onuffer, J. and Horuk, R. 2002. Chemokines, chemokine receptors and small-molecule antagonists: Recent developments. Trends Pharmacol. Sci. 23: 459-467.

Ornitz, D. and Itoh, N. 2001. Fibroblast growth factors. Genome Biol. 2: 3001-3009.

Pennica, D., Swanson, T.A., Welsh, J.W., Roy, M.A., Lawrence, D.A., Lee, J., Brush, J., Taneyhill, L.A., Deuel, B., Lew, M., et al. 1998. WISP genes are members of the connective tissue growth factor family that are up-regulated in wnt-1-transformed cells and aberrantly expressed in human colon tumors. Proc. Natl. Acad. Sci. 95: $14717-14722$.

Pitti, R.M., Marsters, S.A., Lawrence, D.A., Roy, M., Kischkel, F.C., Dowd P., Huang, A., Donahue, C.J., Sherwood, S.W., Baldwin, D.T., et al. 1998. Genomic amplification of a decoy receptor for Fas ligand in lung and colon cancer. Nature 396: 699-703.

Schooltink, H. and Rose-John, S. 2002. Cytokines as therapeutic drugs. J. Interfer. Cyto. Res. 22: 505-516.

Sheridan, J.P., Marsters, S.A., Pitti, R.M., Gurney, A., Skubatch, M., Baldwin, D., Ramakrishnan, L., Gray, C.L., Baker, K., Wood, W.I., et al. 1997. Control of TRAIL-induced apoptosis by a family of signaling and decoy receptors. Science 277: 818-821.

Sonnhammer, E.L., Eddy, S.R., Birney, E., Bateman, A., and Durbin, R. 1998. Pfam: Multiple sequence alignments and HMM-profiles of protein domains. Nucleic Acids Res. 26: 320-322.

Strausberg, R.L., Feingold, E.A., and Klausner, R.D. 1999. The mammalian gene collection. Science 286: 455-457.

Tang, B.L. 2001. ADAMTS: A novel family of extracellular matrix proteases. Intl. J. Biochem. Cell Biol. 33: 33-44.

Williamson, A.R. 1999. The Merck gene index project. Drug Discovery Today 4: 115-122.

Xie, M.H., Holcomb, I., Deuel, B., Dowd, P., Huang, A., Vagts, A., Foster, J., Liang, J., Brush, J., Gu, Q., et al. 1999. FGF-19, a novel fibroblast growth factor with unique specificity for FGFR4. Cytokine 11: 729-735.

Xie, M.H., Aggarwal, S., Ho, W.H., Foster, J., Zhang, Z., Stinson, J., Wood, W.I., Goddard, A.D., and Gurney, A.L. 2000. Interleukin (IL)-22, a novel human cytokine that signals through the interferon receptor-related proteins CRF2-4 and IL-22R. J. Biol. Chem. 275: $31335-31339$

Yamamoto, S., Higuchi, Y., Yoshiyama, K., Shimizu, E., Kataoka, M., Hijiya, N., and Matsuura, K. 1999. ADAM family proteins in the immune system. Immunol. Today 20: 278-284.

Yan, M., Wang, L.C., Hymowitz, S.G., Schilbach, S., Lee, J., Goddard, A., de Vos, A.M., Gao, W.Q., and Dixit, V.M. 2000. Two-amino acid molecular switch in an epithelial morphogen that regulates binding to two distinct receptors. Science 290: 523-527.

Yancopoulos, G.D., Klagsbrun, M., and Folkman, J. 1998. Vasculogenesis, angiogenesis, and growth factors: Ephrins enter the fray at the border. Cell 93: 661-664.

Yang, R.B., Mark, M.R., Gray, A., Huang, A., Xie, M.H., Zhang, M., Goddard, A., Wood, W.I., Gurney, A.L., and Godowski, P.J. 1998 Toll-like receptor-2 mediates lipopolysaccharide-induced cellular signalling. Nature 395: 284-288.

Zhang, Z. and Wood, W.I. 2003. A profile hidden Markov model for signal peptides generated by HMMER. Bioinformatics 19: 307-308

Received February 23, 2003; accepted in revised form July 28, 2003. 
Genome Research 13: 2265-2270 (2003)

\section{The Secreted Protein Discovery Initiative (SPDI), a Large-Scale Effort to Identify Novel Human Secreted and Transmembrane Proteins: A Bioinformatics Assessment}

Hilary F. Clark, Austin L. Gurney, Evangeline Abaya, Kevin Baker, Daryl Baldwin, Jennifer Brush, Jian Chen, Bernard Chow, Clarissa Chui, Craig Crowley, Bridget Currell, Bethanne Deuel, Patrick Dowd, Dan Eaton, Jessica Foster, Christopher Grimaldi, Qimin Gu, Philip E. Hass, Sherry Heldens, Arthur Huang, Hok Seon Kim, Laura Klimowski, Yisheng Jin, Stephanie Johnson, James Lee, Lhney Lewis, Dongzhou Liao, Melanie Mark, Edward Robbie, Celina Sanchez, Jill Schoenfeld, Somasekar Seshagiri, Laura Simmons, Jennifer Singh, Victoria Smith, Jeremy Stinson, Alicia Vagts, Richard Vandlen, Colin Watanabe, David Wieand, Kathryn Woods, Ming-Hong Xie, Daniel Yansura, Sothy Yi, Guoying Yu, Jean Yuan, Min Zhang, Zemin Zhang, Audrey Goddard, William I. Wood, and Paul Godowski

An author, Alane Gray, was inadvertently left off the original author list. The authors apologize for any confusion this may have caused.

Genome Research 13: 1944-1951 (2003)

Detection and Assignment of Mutations and Minihaplotypes in Human DNA Using Peptide Mass Signature Genotyping (PMSG): Application to the Human RDS/Peripherin Gene Cheryl A. Telmer, Adam R. Retchless, Ashley D. Kinsey, Yvette Conley, Brian Rigatti, Michael B. Gorin, and Jonathan W. Jarvik

The second author's name should have appeared as Adam C. Retchless, not Adam R. Retchless. 


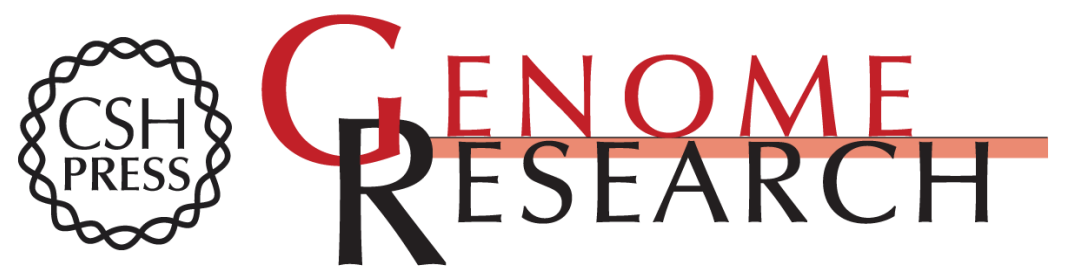

\section{The Secreted Protein Discovery Initiative (SPDI), a Large-Scale Effort to Identify Novel Human Secreted and Transmembrane Proteins: A Bioinformatics Assessment}

Hilary F. Clark, Austin L. Gurney, Evangeline Abaya, et al.

Genome Res. 2003 13: 2265-2270

Access the most recent version at doi:10.1101/gr.1293003

\footnotetext{
Supplemental http://genome.cshlp.org/content/suppl/2003/10/03/1293003.DC1 Material

Related Content Correction for Volume 13, p. 2265

Genome Res. December , 2003 13: 2759

References This article cites 39 articles, 12 of which can be accessed free at: http://genome.cshlp.org/content/13/10/2265.full.html\#ref-list-1

Articles cited in:

http://genome.cshlp.org/content/13/10/2265.full.html\#related-urls

License
}

Email Alerting Receive free email alerts when new articles cite this article - sign up in the box at the Service top right corner of the article or click here.

\section{Affordable, Accurate Sequencing.}

